\title{
Balance assessment in HTLV-1 associated myelopathy or tropical spastic paraparesis
}

\author{
Naiane Araújo Patrício ${ }^{[1]}$, Mônica Andrade Rios ${ }^{[2]}$, Patrícia Carvalho Barbosa ${ }^{[2]}$, \\ Jéssica Ramos Ribeiro ${ }^{[2]}$, Diogo Guedes Vidal ${ }^{[3]}$, Kátia Nunes Sá ${ }^{[4]}$ \\ and Abrahão Fontes Baptista ${ }^{[1,4,5,6]}$
}

\author{
[1]. Universidade Federal da Bahia, Pós-graduação em Medicina e Saúde, Salvador, BA, Brasil. \\ [2]. Escola Bahiana de Medicina e Saúde Pública, Graduação de Fisioterapia, Salvador, BA, Brasil. \\ [3]. Universidade Fernando Pessoa, Unidade de Investigação UFP em Energia, Ambiente e Saúde (FP-ENAS), Porto, Portugal. \\ [4]. Escola Bahiana de Medicina e Saúde Pública, Salvador, BA, Brasil. \\ [5]. Universidade Federal do ABC, Centro de Matemática, Cognição e Computação, São Bernardo, SP, Brasil. \\ Universidade de São Paulo, Laboratório de Investigações Médicas 54 (LIM-54), São Paulo, SP, Brazil.
}

\begin{abstract}
Introduction: A good rating of the device in people with HTLV-1 in this population is essential for accuracy in prescribing data (walking). Thus, this study aimed to analyze the counterpart assessment methods that are best suited to patients with human T-cell lymphotropic virus (HTLV)-1 associated myelopathy or tropical spastic paraparesis (HAM/TSP). Methods: This cross-sectional study related stabilometric and kinematic variables of postural oscillations with Berg's balance scale (BBS) and Timed Up and Go (TUG) in subjects with HAM/TSP compared to asymptomatic subjects. To assess the posterior and lateral postural projection, baropodometry and the Footwork ${ }^{\circledR}$ system was used, and the CVMob system was applied to kinematic parameters. The means comparison tests and correlations were applied with an alpha of 5\%. Results: Thirty-nine subjects (predominantly female) made up the sample. There was an increase in barodopometric oscillations, in the total oscillation area $(\mathrm{p}=0.004)$, in the anteroposterior oscillation in the left $(\mathrm{p}=0.015)$ and right views $(\mathrm{p}=0.036)$, and in the lateral oscillation $(p=0.039)$ in the HAM/TSP group. Moderate correlations were found between oscillation baropodometry and the angular variation of the ankle, as well as with the BBS in the three angles and the TUG for lateral oscillation $(p=0.406)$. Conclusions: Each method has advantages and disadvantages, including cost accuracy. The best resources available at no additional cost for outpatient to use are the kinematic evaluation using a simple smartphone camera and free analysis software, and the TUG.
\end{abstract}

Keywords: Postural balance. Tropical spastic paraparesis. Human T-lymphotropic virus 1. Health evaluation.

\section{INTRODUCTION}

The human T-cell lymphotropic virus (HTLV) infects 10 to 20 million people on all continents, but Brazil is the country with the highest absolute number of known cases ${ }^{1}$. Although the majority of those infected remain asymptomatic, about $5 \%-10 \%$ of patients may progress to neoplastic, inflammatory, or degenerative diseases. HTLV-1 associated myelopathy or tropical spastic paraparesis (HAM/TSP) is very frequent in this population ${ }^{2}$. The posture of people with HAM/TSP is typically altered by spasticity, shortening,

\footnotetext{
Corresponding author: Naiane Araújo Patrício

e-mail: naianearaujopatricio@gmail.com

(iD) https://orcid.org/0000-0002-9616-0898

Received 10 July 2020

Accepted 01 September 2020
}

and weakness of muscle groups in the lower limbs ${ }^{3}$. This pattern affects gait ${ }^{4}$ and balance, causing frequent falls ${ }^{5,6}$.

Balance assessment is, thus, very important in this population, and should be done routinely in the clinical setting to identify potential risks of falls. This can be accomplished by the use of biomechanical measuring instruments or by scales and functional tests. A simple and accurate method is preferred for use in the clinical setting. Biomechanical methods are the gold standard for balance assessment and include the use of force platforms, baropodometry, dynamic posturography and kinematics, and multiaxial stabilometry ${ }^{7}$, most of which are applied in research laboratories with technically trained examiners. Among the available biomechanical tools, the ones that present the best cost-time-accuracy ratio to be adopted in clinical practice are baropodometric ${ }^{8,9,10}$ and kinematic evaluations ${ }^{3,11}$. Both methods can be used to assess orthostatic posture by analyzing stabilometric and angular oscillation data. 
Functional tests and scales are less accurate than biomechanical methods in identifying balance disturbances, but are easier to use in the clinical setting, as they can be used without technological tools or highly trained technical staff. Of these tests, the most popular are the Timed Up and Go (TUG) test, the Romberg Test, the Berg Balance Scale (BBS), and the Dynamic Gait Index ${ }^{7}$. BBS is the most commonly used in HAM/TSP ${ }^{12,13}$. For evidence-based clinical practice, however, it is necessary to select a more accurate, less costly, and briefer application method. Data obtained by a more accurate outpatient method may be favorably accepted by translational science ${ }^{14}$. Also, the systematic use of this method in the follow-up of infected individuals may allow for greater accuracy in balance training and the prescription of walking aids ${ }^{13}$. The present study aimed to analyze which of these balance assessment methods are best suited for people with HAM/TSP.

\section{METHODS}

This cross-sectional study was conducted on subjects registered for research trials and specialized assistance in the city of Salvador, Bahia, Brazil. The study was approved by the Research Ethics Committee of the Catholic University of Salvador under CAAE 49634815.2.0000.5628, constituting a specific objective of a crossover clinical trial. All participants, after being informed of the collection objectives and procedures, signed the consent form that followed the recommendations of the Helsinki Declaration and National Health Council Resolution 466/12.

Data collection was carried out in the biomechanics laboratory of the Catholic University of Salvador, from April 2016 to January 2017 , by a trained team of physiotherapists. The evaluated population was comprised of patients seropositive for HTLV-1, with defined or likely HAM/TSP, according to the guidelines of the World Health Organization (WHO) published in 1988, revised in $1989^{15}$, in addition to the ability to remain in orthostasis for at least 30 seconds. Non-inclusion criteria were cases of co-infection with human immunodeficiency virus or viral hepatitis, pregnancy, psychiatric disorders, rheumatic or orthopedic diseases, other neurological disorders according to the responsible neurologist, and those who had difficulties in understanding the assessment instruments and controls used.

Initially, a sociodemographic questionnaire was applied to obtain clinical information on the subjects' history of falls. Then, participants, dressed in sports or intimate clothes, were positioned onto the baropodometry platform (FootWork Pro, AM cube ${ }^{\circledR}$, Gargas, France), and were instructed to remain stable for 30 seconds with the head straight, eyes open and gaze fixed on a point marked on the wall to guarantee the horizontality of the plane of Frankfort. The baropodometer was calibrated with the weight (Welmy Precision Scale, Welmy, Salvador, Brazil) and stature (Cescorf® stadiometer, Salvador, Brazil) of the participant. For baropodometry evaluation, through the FootWork ${ }^{\circledR}$ software, we considered the total area of oscillation (TAO) in $\mathrm{cm}^{2}$, and anteroposterior (APO) and lateral oscillations (LO) in $\mathrm{cm}$.

Video recordings were performed during all the tests using a video camera (GoPro HERO 3.0, GoPro Inc. ${ }^{\circledR}$, San Mateo, Califórnia, USA) in the sagittal, and left and right views. For the delimitation of the anatomical landmarks, the SAPO ${ }^{\circledR}$ Protocol (http://sapo.incubadora.fapesp.br/portal) was used. The anatomical points were marked using $25 \mathrm{~mm}$ semi-beads affixed with doublesided $\operatorname{Scotch} \AA$ adhesive tape. The video camera was adjusted using an Elgin adjustable height tripod (TEEM® TM 3180, Rio de Janeiro, Brazil). The tripod was positioned three meters from the platform and at half the height of the participant. Subsequently, the video was transferred to a laptop, and the kinematic evaluation was performed using CVMob. The kinematic variables analyzed were body alignment, and hip and ankle angles (Figure $\mathbf{1}$ and Figure 2).

After baropodometry, participants were assessed for balance using the BBS ${ }^{16}$ and then the TUG ${ }^{13,17}$. Briefly, the BBS consists of 14 activities, scored from 0 to 4 , with a maximum value of 56 points. In the TUG, the participant was seated in a standard chair, approximately $46 \mathrm{~cm}$ away from the floor, and then stood up, walked a distance of 3 meters, returned to the chair and sat again. The test was performed once for training, and the result of the second attempt

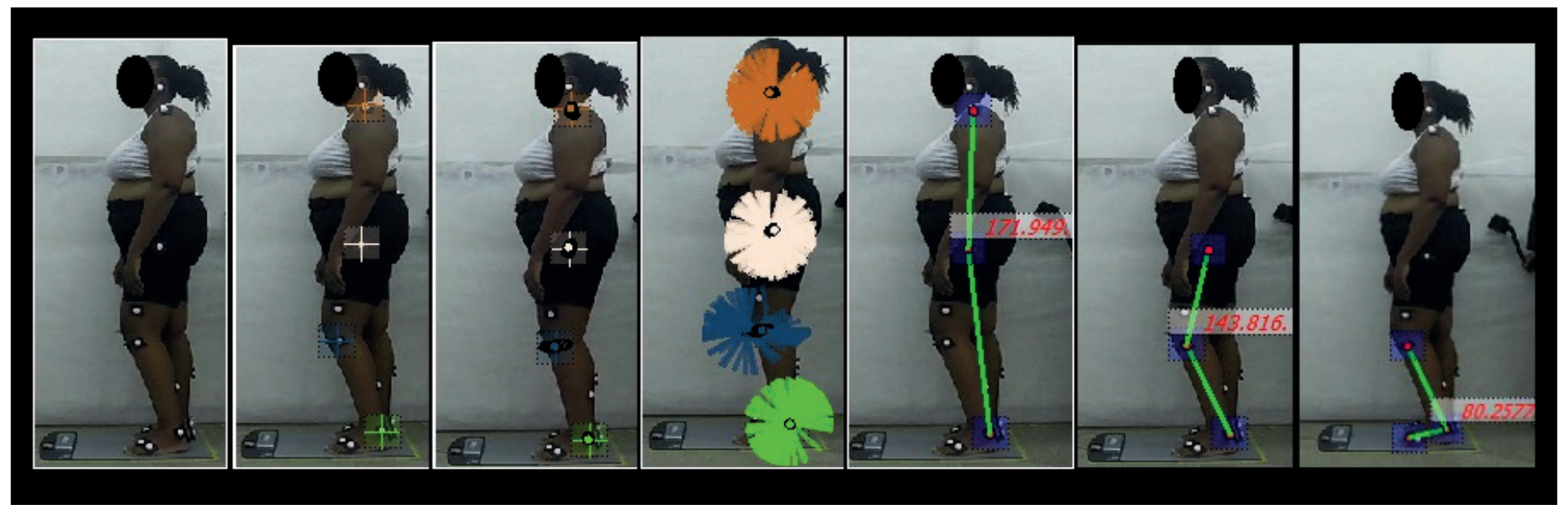

FIGURE 1: Kinematic points of the evaluation (body alignment, hip and ankle angles) of a participant with HAM/TSP, Salvador, Bahia, Brazil, 2017. 


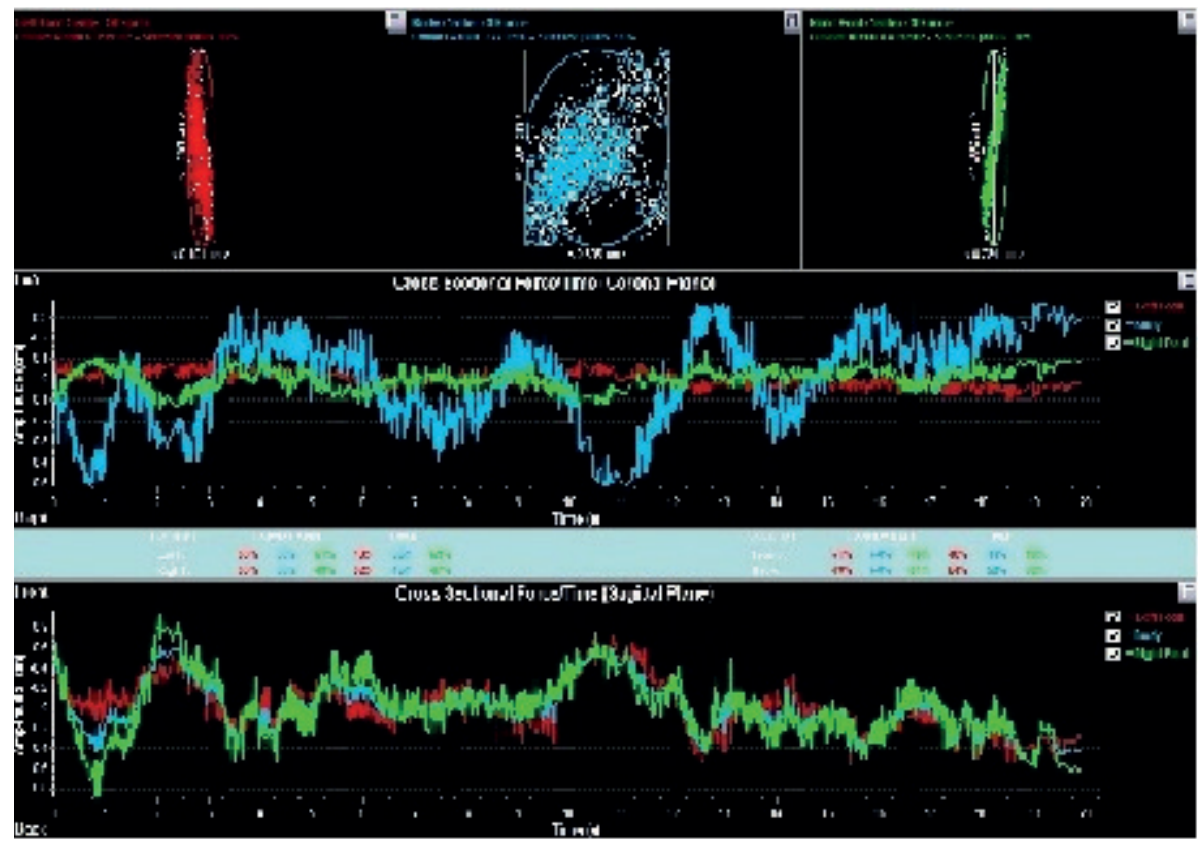

FIGURE 2: Stabilometric evaluation of a participant with HAM/TSP, Salvador, Bahia, Brazil, 2017. Legend: blue color - total area of oscillation of body; red and green color - anteroposterior and lateral oscillations of the feet).

was recorded. The time was digitally monitored. The participants were assessed individually to guarantee privacy and exclusivity.

A sample size calculation was performed according to the online calculator of the Laboratory of Epidemiology and Statistics of the University of São Paulo (LEE), considering a standard deviation of 9.83 of the Berg Scale scores, a between-group difference in the BBS of 10 points ${ }^{18}$, a $5 \%$ alpha value, and study power of $80 \%$. According to these characteristics, a sample size of 12 participants was estimated for two groups, one with HAM/TSP and the other composed of healthy participants. The comparative group was composed of an HTLV seronegative family member or caregiver, systematically assessed by a multidisciplinary team at the reference center.

All data were tabulated and analyzed by the Statistical Package for the Social Sciences (SPSS ${ }^{\circledR}$, IBM SPSS, University of Chicago, USA) version 25.0. Initially, descriptive analyses were performed through the distribution of absolute numbers and proportions for categorical variables, with mean and standard deviation for the normally distributed quantitative variables. The Shapiro-Wilk test was used to test normality. The sociodemographic characteristics of the two groups were compared using the chi-squared test. For continuous variables, the t-test for independent samples was used. For the inferential analyses of the differences in the measures, an unpaired t-test or Mann Whitney U test was used, according to the distribution. To test the correlation, the Spearman's correlation test was applied. The construction of composite variables was based on the compute variable option in SPSS to create a new variable that results from the joining of two. The acceptable level of significance was $5 \%$.

\section{RESULTS}

The sample consisted of 39 people, 26 in the HAM/TSP group and 13 in the comparative group. The mean age was $50.7 \pm 9.8$ years old in the affected group and $49.3 \pm 9.4$ in the accompanying group. Subjects were mostly female, Catholic, single and/or married and with self-reported brown skin color. In the sample, 14 (53.8\%) people with HAM/TSP who used walking aids and 18 (69.2\%) who did not, reported the occurrence of more than two falls in the last three months (Table 1). An average BBS score of $41.7 \pm 7.8$ and a TUG value of $20.5 \pm 9.7$ seconds with differences between groups were observed $(\mathrm{p}<0.001)$. The stabilometric and postural variables were asymmetric between the groups. Differences between groups were observed in the total area of oscillation in the left lateral view $(p=0.004)$, in the anteroposterior oscillation on the left $(p=0.015)$ and right ( $\mathrm{p}=0.036)$, as well as in the lateral-lateral oscillation in the right lateral view $(p=0.039)$. The body alignment angle showed a statistically significant difference in the left $(p=0.002)$ and right $(\mathrm{p}<0.001)$ views, as did the ankle angle in the left lateral view $(\mathrm{p}=0.031)$ (Table 2).

By correlating the baropodometry oscillations and the postural kinematics with the BBS scores, we identified statistically significant differences between the groups, with negative, weak to moderate correlations between the baropodometry oscillations (left lateral view) and the BBS on the left. The HAM/TSP group presented two moderate negative correlations compared to the group without HAM/TSP, in the anteroposterior oscillation in both views. No correlations were found between the postural oscillations and the BBS in both groups. By correlating baropodometry and postural 
TABLE 1: Sample sociodemographic characterization of individuals with and without HAM/TSP, Salvador, Bahia, Brazil, 2017.

\begin{tabular}{|c|c|c|c|c|}
\hline & \multicolumn{2}{|c|}{ HAM/TSP Group 26} & \multicolumn{2}{|c|}{ Comparative group 13} \\
\hline & $\mathbf{N}$ & $\%$ & $\mathbf{N}$ & $\%$ \\
\hline \multicolumn{5}{|l|}{ Sex } \\
\hline Male & 9 & 34.6 & 3 & 23.1 \\
\hline Female & 17 & 65.4 & 10 & 76.9 \\
\hline \multicolumn{5}{|l|}{ Marital Status } \\
\hline Single & 12 & 46.2 & 2 & 15.4 \\
\hline Marriage & 10 & 38.5 & 9 & 69.2 \\
\hline Divorced & 0 & 0.0 & 1 & 7.7 \\
\hline Widower & 4 & 15.4 & 1 & 7.7 \\
\hline \multicolumn{5}{|l|}{ Skin Color } \\
\hline Yellow & 1 & 3.8 & 0 & 0.0 \\
\hline White & 1 & 3.8 & 2 & 15.4 \\
\hline Red & 0 & 0.0 & 1 & 7.7 \\
\hline Brown & 12 & 46.2 & 7 & 53.8 \\
\hline Black & 12 & 46.2 & 3 & 23.1 \\
\hline \multicolumn{5}{|l|}{ Physiotherapy } \\
\hline Yes & 22 & 84.6 & 9 & 69.2 \\
\hline No & 4 & 15.4 & 4 & 30.8 \\
\hline \multicolumn{5}{|l|}{ Physical Activity } \\
\hline Yes & 9 & 34.6 & 8 & 61.5 \\
\hline No & 17 & 65.4 & 5 & 38.5 \\
\hline \multicolumn{5}{|l|}{ Walking Aids } \\
\hline Yes & 14 & 53.8 & 0 & 0.0 \\
\hline No & 12 & 46.2 & 13 & 100 \\
\hline \multicolumn{5}{|l|}{ Lateral Domain } \\
\hline Hight-handed & 23 & 88.5 & 13 & 100 \\
\hline Left-handed & 3 & 11.5 & 0 & 0.0 \\
\hline \multicolumn{5}{|c|}{ Falls (last 3 months) } \\
\hline None & 3 & 11.5 & 8 & 61.5 \\
\hline One & 4 & 15.4 & 2 & 15.4 \\
\hline Two & 1 & 3.8 & 1 & 7.7 \\
\hline More than two & 18 & 69.2 & 2 & 15.4 \\
\hline
\end{tabular}

HAM/TSP: HTLV-1 associated myelopathy or tropical spastic paraparesis.

kinematic oscillations with TUG scores, we identified statistically significant differences between the groups, with positive and moderate correlations between lateral stabilometric oscillation (left lateral view) and TUG in the group with HAM/TSP and moderately strong correlations in the body kinematic oscillation (right lateral view) in both views in the group without HAM/TSP (Table 3).

To verify the existence of a relationship between the different assessment methods, two composite variables were created, i.e. TUG plus kinemetric data and BBS plus stabilometric data. The composite TUG plus kinemetry was correlated with BBS and each one of the stabilometric variables (Table 4).

\section{DISCUSSION}

This study aimed to describe the postural control examination responses in people with HAM/TSP to analyze which of the balance assessment methods are best suited to this population. The results indicate that people living with this neurological disease have greater center of gravity oscillations compared to uninfected individuals, characterized by both increased stabilometric oscillations and body and ankle kinematic angles.

Due to several reports of falls in the sample, people with HAM/ TSP were expected to use among the main strategies to keep the 


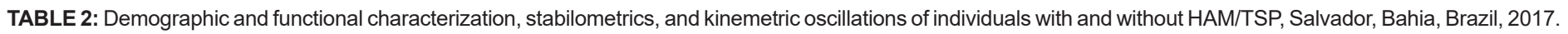

\begin{tabular}{|c|c|c|c|}
\hline & $\begin{array}{l}\text { HAM/TSP } \\
\text { Group } 26 \\
\text { Mean (SD) }\end{array}$ & $\begin{array}{c}\text { Comparative } \\
\text { group } 13 \\
\text { Mean (SD) }\end{array}$ & $p$ \\
\hline Age & $50.7 \pm 9.8$ & $49.3 \pm 9.4$ & 0.659 \\
\hline BMI & $23.7 \pm 6.9$ & $25.8 \pm 5.2$ & 0.246 \\
\hline Berg Scale & $41.7 \pm 7.8$ & $55 \pm 1.5$ & $<0.001$ \\
\hline Timed Up and Go & $20.5 \pm 9.7$ & $8.66 \pm 1.3$ & $<0.001$ \\
\hline \multicolumn{4}{|c|}{ Left Lateral View Stabilometrics Oscillation } \\
\hline Total Area of Oscillations & $5.95 \pm 7.32$ & $1.31 \pm 1.09$ & $0.004^{* *}$ \\
\hline Antero-posterior Oscillations & $2.65 \pm 1.10$ & $1.74 \pm 0.78$ & $0.015^{*}$ \\
\hline Lateral Oscillations & $2.48 \pm 2.81$ & $0.86 \pm 0.44$ & 0.057 \\
\hline \multicolumn{4}{|c|}{ Right Lateral View Stabilometrics Oscillation } \\
\hline Total Area of Oscillations & $4.85 \pm 8.13$ & $1.26 \pm 1.47$ & 0.140 \\
\hline Antero-posterior Oscillations & $2.43 \pm 1.23$ & $1.58 \pm 0.79$ & $0.036^{*}$ \\
\hline Lateral Oscillations & $1.91 \pm 1.70$ & $0.84 \pm 0.47$ & $0.039^{*}$ \\
\hline \multicolumn{4}{|c|}{ Angular Kinemetric Left Lateral Oscillation } \\
\hline Body Alignment & $1.05 \pm 0.81$ & $0.12 \pm 0.79$ & $0.002^{* *}$ \\
\hline Hip Angle & $168.1 \pm 34.4$ & $175.8 \pm 3.65$ & 0.446 \\
\hline Ankle Angle & $83.2 \pm 5.86$ & $87.3 \pm 2.92$ & $0.031^{*}$ \\
\hline \multicolumn{4}{|c|}{ Angular Kinemetric Right Lateral Oscillation } \\
\hline Body Alignment & $1.28 \pm 0.89$ & $1.24 \pm 0.49$ & $0.000^{* *}$ \\
\hline Hip Angle & $167.8 \pm 34.3$ & $173.4 \pm 3.75$ & 0.580 \\
\hline Ankle Angle & $95.9 \pm 5.05$ & $92.8 \pm 2.84$ & 0.052 \\
\hline
\end{tabular}

HAM/TSP: HTLV-1 associated myelopathy or tropical spastic paraparesis; BMI: Body Mass Index; SD: Standard Deviation. *Statistical differences at 0.05 level and ${ }^{* *}$ Statistical differences at 0.001 level.

body in balance on the support base, the hip strategy, since the ankle strategy is generally insufficient in populations with a high risk of falling ${ }^{19}$. However, no large variations were observed in hip angle kinematics. This finding can be explained by good motor control of the pelvic stabilizing muscles, since many participants have previously practiced or currently practice Pilates exercises ${ }^{20,21}$. This sample also usually works on stretching and strengthening plantar flexors, which may increase the efficiency of balance control by the ankle strategy ${ }^{22}$.

Examination of all methods confirmed that this is a population with balance deficits that produces a total oscillation area expansion six times greater than that of uninfected persons. This finding justifies the high occurrence of falls reported by participants, which is in agreement with previous studies ${ }^{23,24}$. Muscle weakness and lower limb spasticity are associated with postural instability ${ }^{3,25}$ and reduced functional mobility ${ }^{13,23}$. Sensory disturbances of the central nervous system with inadequate lower limb muscle function generate postural instability ${ }^{21}$ and, consequently, an increased risk of falls.
Postural sway is considered the basis of the feedback system for recalibration of the center of gravity postural control system and is widely used as a clinical measure of balance capacity ${ }^{26}$. In the HAM/TSP population, a high standard deviation was observed in the stabilometric variables. This finding may express the different stages of disease evolution among the subjects 5 . Among the methods employed, the only one that was able to measure this high dispersion was the baropodometry platform, which has been identified as a valid and reliable resource in cross-sectional balance studies ${ }^{10}$. However, the strong correlation between stabilometric and kinemetric data observed in the present study suggests that the use of angular measurements produce similar results to those of baropodometry when applied in clinical practice.

A three-dimensional kinematic system can also measure oscillations in the three planes ${ }^{27}$. However, free software was not found for this analysis, and its use in the research environment is too costly to be adopted as the gold standard on an outpatient basis. Thus, two-dimensional kinematics may be useful in the evaluation 
TABLE 4: Correlation between TUG plus kinemetric data composite variable and BBS, stabilometric and BBS plus kinemetric data composite variables in individuals with and without HTLV-1, Salvador, Bahia, Brazil, 2017.

\begin{tabular}{lcc}
\hline & $\begin{array}{c}\text { TUG plus Kinemetry } \\
\text { HAM/TSP Group } \\
\mathbf{N}=\mathbf{3 9}\end{array}$ & $\begin{array}{c}\text { TUG plus Kinemetry } \\
\text { Comparative Group } \\
\mathbf{N}=\mathbf{2 6}\end{array}$ \\
\hline BBS plus stabilometry & $\mathbf{- 0 . 4 3 9 ^ { * }}$ & -0.374 \\
BBS & $\mathbf{- 0 . 7 2 8 ^ { * * }}$ & $\mathbf{- 0 . 5 8 1 ^ { * * }}$ \\
$\begin{array}{l}\text { Total Oscillation Area } \\
\text { (Front View) }\end{array}$ & 0.303 & -0.130 \\
$\begin{array}{l}\text { Total Oscillation Area } \\
\text { (Back View) }\end{array}$ & 0.291 & -0.024 \\
$\begin{array}{l}\text { Anteroposterior } \\
\text { Oscillation (Front }\end{array}$ & 0.204 & -0.051 \\
View) & & \\
$\begin{array}{l}\text { Anteroposterior } \\
\text { Oscillation (Back View) }\end{array}$ & $\mathbf{0 . 3 6 5 ^ { * }}$ & 0.094 \\
$\begin{array}{l}\text { Lateral Oscillations } \\
\text { (Front View) }\end{array}$ & $\mathbf{0 . 3 5 6 ^ { * }}$ \\
$\begin{array}{l}\text { Lateral Oscillations } \\
\text { (Back View) }\end{array}$ & 0.267 & 0.211 \\
\hline
\end{tabular}

BBS: Berg balance scale; TUG: Timed up and go test; HAM/TSP: HTLV-1 associated myelopathy or tropical spastic paraparesis. ${ }^{*}$ Correlation significant at 0.05 level and ${ }^{* *}$ Correlation significant at 0.001 level.

of this population ${ }^{11}$, but with restrictions in the data analysis. Despite the limitation of performing only two-dimensional analyses, the CVMob software used in the present study for kinematic analyses, proved useful in the evaluation of stabilometric oscillations at the three selected angles, with moderate correlation with the BBS and with the TUG, regarding lateral oscillation. These findings point to the indication of the use of kinematics with the aid of simple images acquired with smartphone cameras in the follow-up of these patients. With an application time (about 60 seconds for calibration and collection) less than or equal to the scales (30 minutes for BBS and 60 seconds for TUG) and baropodometry (about 90 seconds), it was able to detect the general equilibrium state. Measurements of angular variations, especially the ankle, may serve as a marker of balance based on the ankle strategy according to the 'inverted pendulum' theory ${ }^{28,29}$.

Stabilometry is the most accurate exam due to its ability to perform three-dimensional measurements and analysis, but its cost is around $\$ 5,000$, which makes it impossible to adopt on an outpatient basis, especially for public services in underdeveloped or developing countries and in the time of a world economic crisis. It is worth remembering that HAM/TSP is a condition that affects less favored populations from the socioeconomic point of view ${ }^{1,30}$.

The BBS is the most detailed exam that includes several tasks, but the examiner's verbal commands greatly influences the behavior of the subjects. Besides, the interpretation of the data is subjective and it has a prolonged application time, which can lead to fatigue of the evaluator as well as anxiety in the subject due to the challenge of balancing and referring to previous losses, 
and also an increase in the cost due to the time spent with a specialized professional. The suggested cutoff point for the sample in this exam is 50 points $^{13}$, for those who prefer to adopt it. In which case, it is recommended that the evaluator should be trained and that the same examiner should always apply the scale to compare balance before and after an intervention, to monitor clinical progress, and to prescribe walking aids. Due to the aforementioned limitations, a more objective and quick application measure has become necessary, so the use of short films can be considered to assess the balance of this population since the scores obtained are very close to those obtained by the BBS scale.

On the other hand, the TUG is a quick exam. However, it also depends on the experience of the examiner who guides the subject during data collection. The use of a stopwatch in this test adopts a less subjective variable, which reinforces its value in the dynamic balance examination ${ }^{17}$. Because it does not require a double task, which would increase the risk of falling during the test, it is an accurate and safe balance examination for various populations. A previous study suggested a cutoff point of 12.28 seconds for the HAM/TSP population ${ }^{13}$. The TUG added to the kinematic analysis can complement balance information with greater precision in the follow up of this population.

The TUG plus kinemetric composite variable presented a strong correlation with BBS and BBS plus stabilometric data. This shows that both clinical and biomechanical assessments give the same information and can to be acceptable by clinicians and researchers. The simple smartphone camera kinematics in the lateral view focused on the ankle and the TUG test were complementary measures to assess balance in people with HAM/TSP.

Among the limitations of the present study, it is admitted that the stage of the disease in the sample was not evaluated. If the sample had been more homogeneous, the dispersion measures might not be so high. However, because this is a rare disease with associated sensory disturbances, forming homogeneous samples is very difficult. Nor was the most accurate contemporary examination used for this assessment, which would be a multiaxial force platform for balance examination. However, its high cost and the unavailability of the equipment in the state of Bahia made its application unfeasible. Another aspect that could complete the balance analysis would be electromyography, which was not used in the present study.

We conclude that the HAM/TSP population has a high balance deficit that can be measured by scales and stabilometric and kinematic measurements. Although all forms of evaluation have advantages and disadvantages, varying costs, and different collection times, our findings demonstrate that simple smartphone camera kinematics in the lateral view focused on the ankle and the TUG test were complementary and the best suited measures to assess balance in people with HAM/TSP.

\section{ACKNOWLEDGMENTS}

Acknowledgment the participants of this study for making it possible.

\section{FINANCIAL SUPPORT}

This study was financed in part by the Coordenação de Aperfeiçoamento de Pessoal de Nível Superior - Brasil (CAPES)
- Finance Code 001. Postgraduate Program in Medicine and Health, Faculty of Medicine of Bahia, Federal University of Bahia, Salvador, Bahia, Brazil. AFB receives a level 2 scholarship for scientific production from CNPq, Brazil.

\section{AUTHORS' CONTRIBUTION}

NAP: Creation of the idea that originated the work and elaborate hypotheses, Structuring of the work method, Writing of the manuscript, Coordination of the group that carried out the work, Literature review, Presentation of important suggestions incorporated into the work, Data collection, Analysis of the results statistically, Guiding writing the manuscript, preparing the presentation of the work for a scientific event; Headed the place where the work was carried out, Presented minor suggestions incorporated into the work; MAR: Literature review, Presentation of important suggestions incorporated into the work, Resolution of fundamental problems, Creation of devices to carry out the work, Data collection, Preparation of the presentation of the work for a scientific event, Presentation of the work in a scientific event, Presentation of minor suggestions incorporated to work; PCB: Literature review, Presentation of important suggestions incorporated into the work, Resolution of fundamental problems, Creation of devices to carry out the work, Data collection, Preparation of the presentation of the work for a scientific event, Presentation of the work in a scientific event, Presentation of minor suggestions incorporated to work; JRR: Literature review, Presentation of important suggestions incorporated into the work, Resolution of fundamental problems, Creation of devices to carry out the work, Data collection, Presentation of minor suggestions incorporated into the work; DGV: Writing of the manuscript, Review of the literature, Presentation of important suggestions incorporated into the work, Resolution of fundamental problems of the work, Creation of devices to carry out the work; Analysis of results statistically; Guidance on the writing of the manuscript, Presented minor suggestions incorporated into the work; KNS: Creation of the idea that originated the work and elaborate hypotheses, Structuring of the work method, Orientation and coordination of the work, Writing of the manuscript, Coordination of the group that carried out the work, Literature review, Presented important suggestions incorporated into the work, Resolution of fundamental problems, Creation of devices to perform the work, Data collection, Statistical analysis of results; Orientation of the writing of the manuscript; Work preparation for scientific event; Head the place where the work was performed, Provision of patients or material for work; Got money to do the job, made minor suggestions built into the job; AFB: Creation of the idea that originated the work and elaborate hypotheses, Structuring of the work method, Orientation and coordination of the work, Writing of the manuscript, Coordination of the group that carried out the work, Literature review, Presented important suggestions incorporated into the work, Resolution of fundamental problems, Creation of devices to perform the work, Data collection, Statistical analysis of results; Orientation of the writing of the manuscript; Work preparation for scientific event; Head the place where the work was performed, Provision of patients or material for work; He obtained funds for the work, He presented minor suggestions incorporated in the work. 


\section{CONFLICTS OF INTEREST}

The authors declare that there are no conflicts of interest.

\section{REFERENCES}

1. Gessain A, Cassar O. Epidemiological aspects and world distribution of HTLV-1 infection. Front Microbiol. 2012;3(388):1-23.

2. Proietti F, Carneiro-Proietti A, Catalan-Soares B, Murphy E. Global epidemiology of HTLV-1 infection and associated diseases. Oncogene. 2015;24:6058-68.

3. Macêdo MC, Baptista AF, Galvão-Castro Filho B, Duarte EF, Patrício N, Kruschewsky RA, et al. Postural profile of individuals with HAM/ TSP. Braz J Med Human Health. 2013;2(1):99-110.

4. Franzoi A, Araújo A. Disability profile of patients with HTLV-I associated myelopathy/tropical spastic paraparesis using the Funcional Independence Measure (FIM). Spinal Cord. 2005;43(4):236-40.

5. Yamano Y, Sato T. Clinical pathophysiology of human T-lymphotropic virus-type 1-associated myelopathy/tropical spastic paraparesis. Front Microbiol. 2012;3(389):1-10.

6. Mendes SM, Baptista AF, Sá KN, Andrade DCA, Otero GC, Cavalcanti $\mathrm{JZ}$, et al. Pain is highly prevalent in individuals with tropical spastic paraparesis. Health Care. 2013;1(3): 47-53.

7. Alonso AC, Luna NM, Dionísio FN, Speciali DS, Leme LEG, Greve JMA. Functional balance assessment: review. Medical Express. 2014;1(6):298-301.

8. Vasconcelos BHB, Souza GS, Barroso TGCP, Silveira LCL, Sousa RCM, Callegari B, et al. Barefoot plantar pressure indicates progressive neurological damage in patients with human T-cell lymphotropic virus type 1 infection. PLos One. 2016;21:1-10.

9. Bankoff ADP, Ciol P, Zamai CA, Schimdt A, Barros D. Estudo do equilíbrio corporal postural através do sistema de baropodometria eletrônica. Conexões. 2004;2(2):87-104.

10. Tamburella F, Scivoletto G, Iosa M, Molinari M. Reliability, validity, and effectiveness of center of pressure parameters in assessing stabilometric platform in subjects with incomplete spinal cord injury: a serial crosssectional study. J Neuroeng Rehabil. 2014;11:86.

11. Patrício NA, Macedo MC, Miranda JGV, Pena N, Baptista AF, Sá KN. Postural investigation in individuals with HTLV-1 associated myelopathy/tropical spastic paraparesis. J Clin Eng. 2017;42(3): 136-41.

12. Britto VLS, Correa R, Vincent MB. Proprioceptive neuromuscular facilitation in HTLV-1 associated myelopathy/tropical spastic paraperis. Rev Soc Bras Med Trop. 2014;47(1):24-9.

13. Fonseca EP, Sá KN, Nunes RFR, Ribeiro Júnior AC, Lira SFB, Pinto EB. Balance, functional mobility, and fall occurrence in patients with human T-cell lymphotropic virus type-1-associated myelopathy/tropical spastic paraparesis: a cross-sectional study. Rev Soc Bras Med Trop. 2018;51(2):162-7.

14. Pettibone KG, Balshaw DM, Dilworth C, Drew CH, Hall JE, Heacock $\mathrm{M}$, et al. Expanding the concept of translations research: making a place for environmental health sciences. Environ Health Perspect. 2018;126(7):1-6.
15. Osame M. Review of WHO Kagoshima Meeting and diagnostic guidelines for HAM/TSP. In: Blattner WA. Human Retrovirology: HTLV. New York: Raven Press; 1990. p. 191-6.

16. Miayamoto ST, Junior IL, Berg KO, Ramos LR, Natouri J. Brazilian version of the Berg balance scale. Braz J Med Biol Res. 2004;37:1411-21.

17. Podsiadlo D, Richardson S. The Timed "Up \& Go": a test of basic functional mobility for frail elderly persons. J Am Geriatr Soc. 1991;39:142-8.

18. Arnault VACO, Macêdo M, Pinto EBC, Baptista AF, Galvão Castro B, Sá KN. Virtual reality therapy in treatment of HAM/TSP individuals: randomized clinical trial. Revista Pesquisa em Fisioterapia. 2014;2(4):99-106.

19. Horak, FB. Postural orientation and equilibrium: what do we need to know about neural control of balance to prevent falls? Age Ageing. 2006;35-S2:ii7-ii I.

20. Borges J, Baptista AF, Santana N, Souza I, Kruschewsky R, GalvãoCastro B, et al. Pilates exercises improve low back pain and quality of life in patients with HTLV-1 virus: a randomized crossover clinical trial. J Bodyw Mov Ther. 2014;18(1):68-74.

21. Elias LA, Watanabe RN, Kohn F. Spinal mechanisms may provide a combination of intermittent and continuous control of human posture: predictions from a biologically based neuromusculoskeletal model. PLoS Comput Biol. 2014;10(11):1-7.

22. Macêdo MC, Mota RS, Patrício NA, Baptista AF, Andrade Filho AS, Sá KN. Pain and quality of life in human T-cell lymphotropic virus type 1-associated myelopathy or tropical spastic paraparesis after home-based exercise protocol: a randomized clinical trial. Rev Soc Bras Med Trop. 2019;52:1-8.

23. Facchinetti LD, Araújo AQ, Chequer GL, Azevedo MF, Oliveira RVC, Lima MA. Falls in patients with HTLV-1 associated myelopathy/tropical spastic paraparesis (HAM/TSP). Spinal Cord. 2013;51:222-5.

24. Caiafa RC, Orsini M, Felicio LR, Puccioni-Sohler M. Muscular weakness represents the main limiting factor of walk, functional independence and quality of life of myelopathy patients associated to HTLV-1. Arq Neuro-Psiquiatr. 2016;74(4):280-6.

25. Dias GA, Yoshikawa GT, Koyama RV, Fujihara S, Martins LC, Medeiros $\mathrm{R}$, et al. Neurological manifestations in individuals with HTLV-1associated myelopathy/tropical spastic paraparesis in the Amazon. Spinal Cord. 2016;54(2):154-7.

26. Chisholm E, Perry SD, McIlroy WE. Interlimb centre of pressure symmetry during gait among stroke survivors. Gait Posture. 2011;33(2);238-43.

27. Quixadá AP, Onodera AN, Pena N, Miranda JGV, Sá KN. Validity and reliability of free software for bidimentional gait analysis. Revista Pesquisa em Fisioterapia. 2017;7(4):548-57.

28. Carvalho LR, Almeida GL. Sensorial and cognitive aspects of postural control. Rev Neurociências. 2009;17(2):156-60.

29. Alburquerque-Sendín F, Fernández-de-las-Peñas C, Santos-del-Rey M, Martín-Vallejo FJ. Immediate effects of bilateral manipulation of talocrural joints on standing stability in healthy subjects. Man Ther. 2009; 14(1):75-80.

30. Coutinho IJ, Galvão-Castro B, Lima J, Casteloo C, Eiter D, Grassi MFR. Impacto da mielopatia associada ao HTLV- doença espástica tropical (PET/HAM) nas atividades de vida diária (AVD) em pacientes infectados pelo HTLV-1. Acta Fisiatr. 2011;18:6-10. 